\title{
Object permanence in child and chimpanzee
}

\author{
SUSAN WOOD, KATHLEEN M. MORIARTY, BEATRICE T. GARDNER, \\ and R. ALLEN GARDNER \\ University of Nevada, Reno, Nevada 89557
}

\begin{abstract}
In a repeated-measures design, two infant chimpanzees and three human infants were tested in like manner using the Uzgiris and Hunt (1975) stepwise assessment instrument for the development of object permanence in human infants. Comparisons between chimpanzee and human subjects showed similarities in the number of steps achieved, in the order and rate of achieving the steps, and in the detailed characteristics of searching behavior. These results suggest that the course of development of the concept of object permanence, as described by Piaget, is a very general one.
\end{abstract}

The notion of the permanence of objects, which children develop during the sensorimotor periodfrom birth to about 2 years of age (Piaget, 1952, 1954) - has been a prime focus of attention in the study of infant cognitive development (Gratch, 1975).

The infant's search for hidden objects has been employed to index the major stages of object concept development. Although most research has focused upon human infants, studies of young nonhumans, including chicks (Etienne, 1973), kittens (Gruber, Girgus, \& Banuazizi, 1971), squirrel monkeys (Vaughter, Smotherman, \& Ordy, 1972), macaques (Parker, 1977; Wise, Wise, \& Zimmerman, 1974), and anthropoid apes (Redshaw, 1978), have shown that certain aspects of object permanence occur in the behavior of other species. The results of these animal studies agree in a general way with Piaget's account of sensorimotor development in human infants. The orderly development through stages was supported, since subjects did not typically acquire the behavior of an advanced stage before that of an earlier one. While a similar sequence in the development of object permanence was observed, the various species attained stages at different rates and differed in the level of the object concept (as indicated by Piagetian stage) that they attained. If the nonhuman subjects attained a particular stage, such as Stage IV, the active search for the vanished object (Piaget, 1954), they did so at an earlier age than in the case of the human child. But precise comparisons are ruled out, since none of these studies has employed child controls. Moreover, differences from Piaget's findings, or from the findings of psychometric studies of infants inspired by

Research supported by NSF Grants GB-35586 and BNS 75-17290 and by The Grant Foundation, New York. This article is based on the first author's MA thesis and on a paper she presented at the XXIst International Congress of Psychology, Paris, France, 1976. Tragically, Susan Wood was killed in an automobile accident before she could prepare a version of her work for publication. Susan Wood dedicated her thesis to her mother and her grandmother.
Piaget (Gratch, 1975), are hard to interpret because of discrepancies in the method of testing human and nonhuman subjects (cf. Wise et al., 1974). Thus, the tasks designed for a given stage were not analogous (Etienne, 1973; Gruber et al., 1971; Vaughter et al., 1972); only a few tasks, rather than a set of tasks that would permit investigation of all six stages, were carried out (Etienne, 1973; Gruber et al., 1971; Parker, 1977; Redshaw, 1978; Vaughter et al., 1972); and as many as 100 trials or invariant repetitions of a given task were common with nonhuman subjects, whereas 10 trials or less were usual with human infants (Vaughter et al., 1972; Wise et al., 1974). The present study was designed to provide data on the development of object permanence in chimpanzees that could be compared directly with data for human infants.

Uzgiris and Hunt (1975) have constructed and standardized ordinal scales of infant development based on the eliciting situations and critical actions that Piaget described for the sensorimotor period (Piaget, 1952, 1954). For the development of object permanence, the scale ranges from series A (Piaget's Stages I and II), in which the evidence of object permanence comes from observations of visual pursuit of an object as it disappears, to series E (Piaget's Stage VI), in which the infant's pattern of search must follow the sequence of invisible hidings. Success on any step of the scale implies the ability for earlier steps, and success on higher steps of the scale is agerelated (Uzgiris \& Hunt, 1975).

The present study examined object permanence in infant chimpanzees and human infants using the Uzgiris and Hunt (1975) instrument. The behavioral development of infant chimpanzees shows considerable similarity to that of humans (Jolly, 1973). Chimpanzees have a period of infancy comparable to, or even longer than, that of human infants. In the wild, infant chimpanzees are often not weaned until 4 years of age or older, and may continue to join their mother in her sleeping nest at night even though they 
have been weaned. Wild chimpanzees have also exhibited characteristics of object permanence seen in human infants, for example, searching for objects invisibly hidden or displaced (Goodall, 1971), as has an adolescent caged chimpanzee (Mathieu, Bouchard, Granger, \& Herscovitch, 1976). Under appropriate environmental conditions, chimpanzees can comprehend and use sign language, comparably to very young children (Gardner \& Gardner, 1978).

The two young chimpanzees studied here were reared in an enriched home-like environment. They were exposed to many of the objects and events that human infants encounter during the early years of their development. In addition, they were exposed to sign language very soon after birth, and started signing at a very early age (Gardner \& Gardner, 1975b). Because their rearing conditions permitted comparable methods of testing, these chimpanzees seemed well suited for an investigation of the cognitive development of human and nonhuman infants, and such an investigation would test the scope of Piaget's account of "how the budding intelligence constructs the external world"' (Piaget, 1954, p. 3).

\section{METHOD}

\section{Subjects}

Two chimpanzees, C-18 and C-30, and three human infants, $\mathrm{H}-8, \mathrm{H}-18$, and $\mathrm{H}-24$, served as subjects in this experiment. The infant chimpanzees were also serving as subjects in a concurrent investigation of two-way communication using American Sign Language (Gardner \& Gardner, 1975b). C-18, a male, was 18 months old at the onset of testing and 21 months old when testing was completed; C-30, a female, was 30 months at the onset and 32 months at completion. The human infants $-\mathrm{H}-8$, a female, $\mathrm{H}-18$, a male, and $\mathrm{H}-24$, a female-were children of members of the university community. Their ages at the onset of testing were 8,18 , and 24 months, respectively; at test completion, they had become 11,21 , and 25 months old.

\begin{abstract}
Apparatus
All experimental manipulations were made on a cloth-covered $\mathrm{U}$-shaped board $(1.0 \times 1.5 \mathrm{~m})$, placed either on an infant feeding table or on the floor. The subject sat within the $U$ of the apparatus, facing the experimenter. The observer sat to the left of the subject, between the subject and the experimenter. At the start of each session, the subject was seated in the feeding table. If the infant became restless in the feeding table, the board was moved to the floor and testing was continued with a minimum of disturbance. Wash cloths $(.3 \times .3 \mathrm{~m})$, of the same pattern but different colors, were used as covers. The texture of the cloths was such that when they were bunched up a little as they were placed on the board they kept their shape and eliminated any form cues. A variety of small toys and trinkets, such as a whistle, a friction toy, a squeaky doll, a safety snap, beads, a ball, and a key, were used as lures. A felt-lined beaker, large enough to conceal the lures, was used to enable invisible hidings, with a minimum of auditory cuing.
\end{abstract}

\section{Design}

Uzgiris and Hunt (1975), using a cross-sectional design, tested subjects ranging in age from 1 to 23 months, with 15 tasks which comprise Scale 1: The Development of Visual Pursuit and the Permanence of Objects (Appendix A). Each infant was tested with a subset of the tasks comprising the scale, and this subset was chosen to be appropriate to his age. In the present study, the five subjects were tested with each of the 15 tasks. The performance of C-18 was compared with that of the younger, older, and age-matched human infant. The performance of C-30 was compared with that of the 18-month-old and the 24-month-old child. Since the Uzgiris and Hunt scales were designed for infants 24 months or younger, and H-24 was at ceiling performance on all the tasks, it was decided not to test an age-match for the older chimpanzee, that is, a 30-month-old child.

The tasks were presented in the sequence listed in Appendix A, except that task order was varied by interchanging Tasks 1 and 2 with Tasks 8 and 9 on at least one session for each subject.

Each task was administered for six sessions, or until the subject attained the criterion of success (detailed below). Within each session, tasks were administered until they became too difficult for the subject, as indicated by his failure to respond to a given task within $60 \mathrm{sec}$ of its presentation, even though he might resume responding when the previously completed task was retested.

The six sessions were scheduled 14-18 days apart. When performance on all 15 tasks was being measured, it was necessary to divide the session in two, and these two parts, which were administered with an interval of $24-48 \mathrm{~h}$, were considered one session.

\section{Tasks}

The appendix (after Uzgiris \& Hunt, 1975, pp. 206-209) outlines the 15 experimental tasks administered to each subject. Tasks 1 and 2 are visual pursuit tasks. Task 3 involves finding an object that has been partially covered. In Tasks 4-7, the subject is required to find an object under one of the covers, when there are one, two, or three covers present. All of the above cases involve visible displacement. In Task 8 , there are successive visible displacements, that is, the object is placed in the experimenter's hand and passes from left to right (or vice versa) under one cover, out again, under a second, out again, and then deposited under the third, with the object made visible between covers. In Task 9, the object is wrapped in one cover, then covered by the second and third. Tasks 10-13 differ from Tasks 4-7 in that the displacements are invisible; the object is first concealed in the felt-lined beaker or the experimenter's hand and then deposited under the cover, after which the empty hand or container is removed and made available to the subject for inspection. Task 14 resembles Task 8 except that the displacement is invisible. Task 15 involves concealing the object and depositing it under the first cover (rather than the third, as in Task 14), and then continuing to move the hand under the second and third covers, pausing for as long as it would take to deposit the object. Task 15, considered the definitive test for the concept of object permanence (Uzgiris \& Hunt, 1975), is presented immediately subsequent to two or more successful trials on Task 14.

For each task, Uzgiris and Hunt (1975) described "the infant actions which the situation has elicited according to our observations" (Appendix A). The three to six actions that they describe for a given task are mutually exclusive responses to the displacement of the object by the experimenter. For every task, one of the actions (or two, in the case of Tasks 2, 10, and 14) was indicated by an asterisk. Uzgiris and Hunt refer to these as "critical actions." By conducting a scaling analysis on the data from tests with human infants. Uzgiris and Hunt found that the performance of the critical actions indicated achievement of a step in the ordinal scale of development of object permanence (Uzgiris \& Hunt, 1975).

\section{Procedure}

The subjects were tested individually in their homes. In addition 10 the experimenter and the observer, the mother and, sometimes, the father were present for the human subjects. Both the experimenter and the observer visited the infants and played with them prior to testing and between test sessions. Only the experimenter and observer were present for the chimpanzees, and both were familiar caretakers of the chimpanzees.

Following a short period of play, testing began, with tasks presented in a preassigned order. The observer recorded the subject's 
searching behavior for the first minute following the displacement of the object by the experimenter, or until the subject touched the object, whichever happened firsi. The secord for each trial consists of the time of occurrence of one of the mutually exclusive infant actions for the task listed in Appendix A, or the time of occurrence of some "other" action not listed by Uzgiris and Hunt (1975). Note that contacting the object is characteristic of more than one of the listed actions, not of the critical action alone. Following the completion of the three, four, or five repetitions or trials for each task specified by Uzgiris and Hunt (Appendix A), the occurrence of mistrials ${ }^{1}$ was determined, and the eliciting situation repeated the required number of times. A mistrial was declared when the subject failed to attend to any part of the trial or interfered with the covers or lures before displacement was completed. When the necessary number of complete trials had been run, the experimenter proceeded to the next task. All 15 tasks were administered in a similar fashion, until the test was completed or the subject failed to respond to a particular task, at which time an easier one was substituted. If the latter was not completed, testing was terminated. If the easier task was completed, the previously failed task was again attempted.

Trials were interspersed with signing, talking, and play with the objects, the experimenter, and the observer. Objects were changed frequently, to keep the subject's attention. On some trials, the experimenter encouraged the subject to find the object by speaking or signing, as in, "Where is the key?" or "Please give Susan the doll." In the case of the children, the mothers involved themselves in the testing, and also made encouraging remarks.

All the subjects participated in the testing readily, and, on at least one occasion per subject, both the children and the chimpanzees hid the test object and waited for the experimenter to find it. The chimpanzees were the more cooperative subjects, in the sense that testing proceeded more efficiently, with less intertrial activity.

The procedure involved face-to-face interaction between the subjects and the experimenter and observer, as is standard in Piagetian testing and usual in most intelligence testing of young children. In such face-to-face testing procedures, there is the possibility of cuing the subjects by the adult's direction of gaze (Gardner \& Gardner, 1975a). In the present study, which followed the directions for arranging the examination situation specified by Uzgiris and Hunt (1975), this possibility of cuing existed, but it was, of course, comparable for the children and the chimpanzees. It should be noted that cuing by direction of gaze presents the most serious problems when the correct response involves a choice among limited alternatives that are spatially distinct, and that aspects of searching other than its location distinguish the critical action from alternative actions in many of the object permanence tasks (Appendix A).

\section{Scoring System and Criterion}

In the present study, a trial was scored correct if the subject performed, within $1 \mathrm{~min}$ from the time of hiding, one of the critical actions, indicated by an asterisk in Appendix A. The criterion of success for each task was correct performance over three consecutive testing sessions with no more than one incorrect trial on no more than two of the three consecutive sessions. Once a subject reached criterion on a task, he or she was not tested with that task in subsequent sessions.

\section{RESULTS}

\section{Comparisons Between Child and Chimpanzee Subjects}

(1) Tasks 1 and 2 examined the development of visual pursuit. Inspection of the data indicated that all five subjects responded inconsistently to these two tasks, by following the objects on some trials but not on others. Tasks 1 and 2 are typically mastered by human infants at age 1 and 2 months, respectively (Uzgiris \& Hunt, 1975, p. 105). The inconsistency in responding was probably due to the age of the subjects, since Uzgiris and Hunt have noted that "once an infant has achieved higher levels of organization in his actions elicited by our situations, it becomes very difficult to get those situations to elicit the earlier, cruder patterns of behavior"' (1975, pp. 125 126). Therefore, scores for the first two tasks were discarded from the analysis.

(2) All five subjects achieved the criterion of success on most of the remaining tasks, within six testing sessions. The youngest child, $\mathrm{H}-8$, achieved criterion on Tasks 3 through 12 , the next child, $\mathrm{H}-18$, on Tasks 3 through 14, and the oldest child, $\mathrm{H}-24$, on all the tasks, 3 through 15 . The performance of the chimpanzee $\mathrm{C}-18$ was like that of the age-matched human subject in that $\mathrm{C}-18$ also achieved criterion on Tasks 3 through 14. The performance of C-30 was like that of the oldest child, since both achieved criterion on all the tasks.

(3) For a more detailed comparison of the subjects' performance on object permanence tasks, success with each task was graded according to the number of sesions - 3, 4, 5, 6, or $>6$-in which criterion was reached. (Since the criterion required performance of the critical actions on three consecutive sessions, no subject could achieve criterion on any task before Session 3.) Table 1 shows the median number of sessions required for the subjects to reach criterion on object permanence tasks, with the tasks grouped into series, under an identifying heading, following Uzgiris and Hunt (Appendix A). It can be seen that there were regularities in achieving the criterion; younger subjects required more sessions to reach criterion than did older ones, and the subjects required more sessions to reach criterion on the more advanced tasks.

Table 1 also shows that the performances of C-18

Table 1

Median Number of Sessions Required to Reach Criterion on Object Permanence Tasks

\begin{tabular}{lrrrrr} 
& & \multicolumn{3}{c}{ Subject } \\
\cline { 2 - 5 } & H-8 & H-18 & H-24 & C-18 & C-30 \\
\hline Search for simply hidden objects (Tasks 3-7) & 3 & 3 & 3 & 3 & 3 \\
Search following more complex hidings (Tasks 8 and 9) & 4.5 & 3.5 & 3 & 3 & 3 \\
Search following an invisible displacement (Tasks 10-13) & 6 & 4 & 3 & 4.5 & 3.5 \\
Search following successive invisible displacements (Tasks 14 and 15) & $>6$ & $>6$ & 3 & $>6$ \\
\hline
\end{tabular}

Note-The minimum number of sessions required to reach criterion was three. 
and $\mathrm{H}-18$, the age-matched child and chimpanzee, were highly similar. In terms of their performance on object permanence tasks, 3 through 15, these two subjects were closer to each other than either was to any other subject, whether child or chimpanzee. The oldest child achieved the criterion on all tasks in Session 3, the minimum number of sessions. The performance of chimpanzee C-30 was like that of the oldest child, except that C-30 lagged 2.5 sessions behind $\mathrm{H}-24$ in attaining criterion on the most advanced tasks, Tasks 14 and 15.

(4) For every trial of every task, the response of the subjects was identified as one of the lettered infant actions in Appendix A, or as some "other" action, not listed by Uzgiris and Hunt (1975). As shown in Table 1, the two oldest subjects achieved criterion on almost all the tasks in the minimum number of testing sessions; hence, most of their responses throughout testing consisted of critical actions only $-96 \%$ in the case of $\mathrm{H}-24$ and $92 \%$ in the case of C-30. Similarly, most of the subjects achieved criterion on the less advanced tasks in the minimum number of sessions, and $88 \%$ of the responses to Tasks 3-11, throughout testing, consisted of critical actions only. For an analysis of incorrect responses, then, the relevant data come from the performance of $\mathrm{H}-18$ and $\mathrm{C}-18$, on the more advanced tasks, Tasks 12-15. (H-8 usually terminated testing before the advanced tasks could be administered.) Table 2 shows that the distribution of responses for the age-matched child and chimpanzee in terms of correct responses, various types of incorrect responses, and "other" responses, throughout the six testing sessions, was remarkably similar. This was so both in terms of preferences for types of incorrect responses and in terms of preference among alternative correct responses, as in the case of Task 14, where action $\mathrm{c}$ and action $\mathrm{d}$ are both correct.

(5) For each task, response latency during the three criterion sessions was used to compare the subjects. Median response time was brief, ranging from 2 to $15 \mathrm{sec}$, in the case of children, and from 1 to $13 \mathrm{sec}$, in the case of the chimpanzees. Most of the tasks yielded latencies $<6 \mathrm{sec}$; only Task 9 and Task 15 consistently produced latencies longer than this, both for children and for chimpanzees. The effect of age on response latency was not significant.
On all but two tasks, the chimpanzees responded faster than the children. Using the Wilcoxon matchedpairs signed ranks test (Siegel, 1956), each chimpanzee was compared with the child that had reached criterion on the same tasks. The difference between $\mathrm{H}-18$ and C-18 was significant $(T=2, p<.01)$, as was the difference between $\mathrm{H}-24$ and $\mathrm{C}-30(\mathrm{~T}=7, \mathrm{p}<.02)$.

\section{Comparisons with Infants Tested by Uzgiris and Hunt}

(1) The order of mastery of tasks, as measured in the present study, reflects the ordered pattern of infant achievements on the steps of the Uzgiris and Hunt scale. ${ }^{2}$ To test this correspondence, the scores of Subjects $\mathrm{H}-8, \mathrm{H}-18, \mathrm{C}-18$, and $\mathrm{C}-30$ were ranked according to the number of sessions required for reaching criterion on each of the tasks. Only those tasks in which the subject did indeed attain the criterion of success were ranked. ${ }^{3}$ (Subject H-24 reached criterion on all tasks in the minimum number of sessions; therefore, her data were not used for rank ordering the tasks.) The hypothesis that the order of mastery of tasks by the child and chimpanzee subjects of the present study would correspond to the ordered steps of the Uzgiris and Hunt scale was tested by computing Kendall's rank correlation coefficient $\tau$ (tau) for ordinal data (Siegel, 1956). The correlations were positive and significant for $\mathrm{H}-8(\tau=.85, \mathrm{p}<.01)$ and $\mathrm{H}-18(\tau=.64, \mathrm{p}<.025)$, as well as $\mathrm{C}-18(\tau=.68, \mathrm{p}<.025)$ and $\mathrm{C}-30(\tau=.61$, $p<.01)$. The order of mastery followed the ordered steps of the scale, except that Task 7, for H-8, H-18, $\mathrm{C}-18$, and $\mathrm{C}-30$, and Task 8 , for $\mathrm{H}-8$ and $\mathrm{H}-18$, were mastered one or two sessions after Task 9.

(2) The data for Tasks 3 through 15 showed that, in every case, older subjects matched the performance of younger subjects, or surpassed it by succeeding on the task before the younger one had done so. In particular, for C-30 and C-18, Tasks 3 through 10 were mastered in the same testing session for both, while Tasks 11 through 15 were mastered in an earlier session by the older chimpanzee. For the child controls also, performance on the later tasks appeared to be more sensitive to the effects of age.

(3) The age at which the majority of infants tested by Uzgiris and Hunt showed the critical actions indicative of a step in the scale also affords a basis for

Table 2

Distribution of Responses for the Age-Matched Child and Chimpanzee on Advanced Tasks

\begin{tabular}{|c|c|c|c|c|c|c|c|c|c|c|c|c|c|c|c|c|c|}
\hline \multirow[b]{3}{*}{ Subject } & \multicolumn{17}{|c|}{ Action } \\
\hline & \multicolumn{4}{|c|}{ Task 12} & \multicolumn{4}{|c|}{ Task 13} & \multicolumn{5}{|c|}{ Task 14} & \multicolumn{4}{|c|}{ Task 15} \\
\hline & a & b & $c^{*}$ & Other & $\mathrm{a}$ & $\mathrm{b}$ & $\mathrm{c}^{*}$ & Other & a & b & $c^{*}$ & $\mathrm{~d}^{*}$ & Other & $\mathrm{a}$ & $\mathrm{b}$ & $c^{*}$ & Other \\
\hline$H-18$ & 2 & 2 & 10 & 1 & 4 & 3 & 22 & 0 & 0 & 0 & 5 & 14 & 1 & 3 & 2 & 6 & 1 \\
\hline C -18 & 2 & 1 & 14 & 1 & 1 & 4 & 20 & 0 & 0 & 0 & 2 & 14 & 4 & 4 & 3 & 6 & 2 \\
\hline
\end{tabular}

Note-See Appendix A. *The action that must be performed for a trial to be scored correct. 
comparison with the subjects of the present study. At test completion, both $\mathrm{C}-18$ and $\mathrm{H}-18$ were 21 months old and had attained criterion on Task 14 but not on Task 15. This agrees with the age information on infants tested by Uzgiris and Hunt (1975), who attained Step 14 at 21-22 months. At test completion, H-8 had attained criterion on Task 12 but not on Task 13, and was 11 months old. She appears to be advanced in comparison with Uzgiris and Hunt subjects, who attained Step 12 at age 14 months. (Uzgiris and Hunt did not present age information for Step 15, attained by $\mathrm{H}-24$ and $\mathrm{C}-30$.)

(4) On the basis of their experience in testing infants with the object permanence scale, Uzgiris and Hunt (1975) listed the various actions that subjects might show in each situation, but warned that "Infants being reared in other cultures or in settings other than homes may well exhibit actions not listed"' (p. 145). A place for noting "other" actions was provided in their examination record forms, and in ours. In the present, comparative study, "other" actions accounted for $5 \%$ of the searching responses recorded for the child subjects and $7 \%$ of the searching responses of the chimpanzees; the actions expected by Uzgiris and Hunt accounted for all remaining responses.

Certain elaborations of searching by the child and chimpanzee subjects were also observed and reported by other investigators of object permanence. Thus, in Task 10, when the lure is first placed in a beaker and then placed under the cover and deposited there, children first look in the beaker and then under the cover (Miller, Cohen, \& Hill, 1970; Uzgiris \& Hunt, 1975). In the present study, this behavior was recorded in early sessions for C-18 and throughout testing for H-8. Both Miller et al. (1970) and Uzgiris and Hunt (1975) consider this double search to be characteristic of infants who are in a transitional stage, having mastered Task 9 but not yet mastered Task 10. This detail of searching behavior in invisible displacement tasks was also observed by Piaget, who used it to infer processes underlying the development of the object concept (Piaget, 1954).

\section{DISCUSSION}

Clearly, the Uzgiris and Hunt instrument for assessing psychological development in infants is a robust one. Through successive revisions of the instrument, Uzgiris and Hunt produced a series of tests of object permanence in which there was a sequential order of successful performance, and in which successful performance on more advanced tests was related to the age of the subject. We were able to confirm these findings, with a different design and for a different species.

The Uzgiris and Hunt instrument is based on Piaget's description of stages in the development of concepts of objects, space, and causality in human infants. Comparative psychologists have recognized that these concepts are useful, and not for children alone: "Animals live in the same physical world and any practical understanding of the general principles according to which this world is organized may provide them with some adaptive advantage" (Etienne, 1973 , p. 385). Indeed, the behaviors that demonstrate certain advanced stages of the object concept and concepts of space (Piaget, 1954) can be recognized as the solutions to the delayed response problems and detour problems, which are classical tasks in comparative psychology. However, what Piaget emphasizes is the difference between adult concepts and infant concepts of objects, space, and so on, and his main interest is in the changes of these concepts with age. The present study suggests that the course of development of the object concept that he envisioned, based on observations of his own three infants, is a very general one, indeed.

Using the Uzgiris and Hunt instrument, two young chimpanzees and three young children were tested in like manner. The results showed similarities in the number of steps achieved, in the order and rate of achieving steps, and in detailed characteristics of searching behavior. The differences that appearedin response latency and in the greater number of sessions that the oldest chimpanzee required to achieve criterion on the most advanced tasks-did not seem major. Overall, we found that for home-reared chimpanzees, as for children, the object concept develops gradually and in an orderly sequence that requires many months to complete. The remaining five scales of Uzgiris and Hunt (1975) should provide a broader basis of comparisons of early cognitive development in human and nonhuman primates. The use of the scales for comparisons between nonhuman primates would be of considerable interest, as would be the use of the instrument to compare the effects of rearing in a particular species, for example laboratory-reared chimpanzees with those reared in home-like environments. While Ameslan was used to communicate with the chimpanzees during the present study, testing in a Piagetian mode beyond the sensorimotor period depends even more on verbal directions and verbal replies. Thus, comparative testing at more advanced levels of cognitive development becomes possible when there are nonhuman subjects that use sign language as a means of two-way communication. Although cognitive development during the sensorimotor period appears similar for child and chimpanzee, at least as far as object permanence is concerned, developments beyond this period may very well reveal differences.

\section{REFERENCES}

ETrivi, A. S. Developmental stages and cognitive structures at determinants of what is learned. In R. Hinde \& J. Stevenson- 
Hinde (Eds.), Constraints on learning. New York: Academic Press, 1973.

Garbntr, B. T., \& Garintri, R. A. Evidence for sentence constituents in the early utterances of child and chimpanzee. Journal of Experimental Psichology: General. 1975, 104, 244-267. (a)

Gardnfr, R. A., \& Gardnkr, B. T. Early signs of language in child and chimpanzee. Science, 1975, 187, 752-753. (b)

Gakinnkr, R. A., \& Garinnkr, B. T. Comparative psychology and language acquisition. Annals of the New York Academy of Sciences, 1978, 309, 37-76.

Goomali, J. v. I. In the shadow of man. Boston: Houghton Mifflin, 1971

Gratc1, G. Recent studies based on Piaget's view of object concept development. In L. B. Cohen \& P. Salapatek (Eds.), Infant perception: From sensation to cognition. New York: Academic Press, 1975.

Gruber, H. E., Girciss, J. S., \& Banunzizi, A. The development of object permanence in the cat. Developmental Psychol. og. $, 1971,4,9-15$

Jot, Y, A. The study of primate infancy. In J. Bruner \& $\mathrm{K}$. Connolly (Eds.), The growth of competence. London: Academic Press, 1973.

Matuleu, M., Bouchand, M.-A., Grancian, L., \& Hriscovitch, J. Piagetian object permanence in Cebus capucines, Lagothrica flavicauda, and Pan troglodvtes. Animal Behaviour, 1976, 24, 585-588.

Mulfr, D. J., Cohren, L. B., \& Hilı, K. T. A methodological investigation of Piaget's theory of concept development in the sensorimotor period. Journal of Experimental Child Psychology, $1970,9,59-85$

PARKrR, S. T. Piaget's sensorimotor series in an infant macaque: A model for comparing unstereotyped behavior and intelligence in human and nonhuman primates. In S. Chevalier-Skolnikoff \& F. E. Poiricr (Eds.), Primate bio-social development: Biological, social, and ecological determinants. New York: Garland, 1977.

\section{APPENDIX A}

\section{Scale 1: The Development of Visual Pursuit and the Permanence of Objects, from Uzgiris and Hunt (1975)}

A. Visual pursuit of slowly moving objects

\section{Following a slowly moving object through a 180-deg $\operatorname{arc}(3)$}

a. Does not follow object

b. Follows jerkily through part of arc

c. Follows smoothly through part of arc

*d. Follows object smoothly through complete arc

2. Noticing the disappearance of a s/ow/ mosing object (3)

a. Does not follow to point of disappearance

b. Loses interest as soon as object disappears

*c. Lingers with glance on point of disappearance

*d. Returns glance to starting point after several presentations

e. Searches around point of disappearance

B. Search for simply hidden objects

3. Finding an object which is partially covered (3)
PIAcikT, J. The origins of intelligence in children. New York: Norton, 1952.

Pinciet, J. The construction of reality in the child. New York: Basic Books, 1954.

ReDshaw, M. Cognitive development in human and gorilla infants. Journal of Human Evolution, 1978, 7, 133-141.

Sicgel, S. Nonparametric statistics. New York: McGraw-Hill, 1956.

UzGiris, I. C., \& Hunt, J. McV. Assessment in infancy. Chicago: University of Illinois Press, 1975.

Vaughter, R. M., Smotherman, W., \& Ordy, J. M. Development of object permanence in the infant squirrel monkey. Developmental Psychology, 1972, 7, 34-38.

Wise, K. L., Wisk, L. A., \& Zimmerman, R. R. Piagetian object permanence in the infant rhesus monkey. Developmental Psvchologv, 1974, 10, 429-437.

\section{NOTES}

1. The percentage of total trials that were mistrials was very low, both in the case of human subjects (.02) and chimpanzee subjects (.01).

2. Uzgiris and Hunt did not include the data for Task 5 and Task 8 in their scaling analysis, because the responses considered to be critical actions for these two steps were noted too infrequently. Therefore, in the present analysis, Task 5 and Task 8 were omitted when calculating $\tau$ for each subject.

3. Achieving criterion on a given task $k_{i}$ in the present study is equivalent to achieving a step; on the Uzgiris and Hunt scale of of object permanence. Uzgiris and Hunt prefer to use the step terminology, so we have used it when citing their findings and conclusions.

(Received for publication January 25, 1979; revision accepted July 20,1979 .)

a. Loses interest

b. Reacts to the loss, but does not obtain object

*c. Obtains the object

\section{Finding an object which is completely covered (3)}

a. Loses interest

b. Reacts to loss, but does not obtain object

c. Pulls screen, but not enough to obtain object

*d. Pulls screen off and obtains object

\section{Finding an object completely covered in two places (3)}

a. Loses interest

b. Searches for object where it was previously found

${ }^{*}$ c. Searches for object where it is last hidden

\section{Finding an object completely covered in two places alternately (3)}

a. Becomes perplexed and loses interest

b. Searches haphazardly under one or both screens

${ }^{*} c$. Searches correctly under each of the screens

\section{Finding an object completely covered in three places} (5)

a. Loses interest 
b. Searches haphazardly under some or all screens

*c. Searches directly under correct screen

C. Search following more complex hidings

8. Finding an object after successive visible displacements (3)

a. Does not follow successive hidings

b. Searches only under the first screen

c. Searches under screen where object was previously found

d. Searches haphazardly under all screens

e. Searches in order of hiding

*f. Searches directly under the last screen in path

9. Finding an object under three superimposed screens (3)
a. Loses interest
b. Lifts one or two screens, but fails to find object
*c. Removes all screens and obtains object

D. Search following an invisible displacement

10. Finding an object following one invisible displacement (3)
a. Loses interest
b. Reacts to loss, does not search
c. Searches only in the box
* $d$. Checks the box and searches under the screen
*e. Searches under the screen directly

11. Finding an object following one invisible displacement with two screens (3)

a. Searches only in box

b. Searches under screen where object was previously found

*c. Searches directly under correct screen
12. Finding an object following one invisible displacement with two screens alternated (3)

a. Loses interest

b. Searches haphazardly under screens

*c. Searches directly under correct screen

13. Finding an object following one invisible displacement with three screens (5)
a. Loses interest
b. Searches haphazardly under all screens
${ }^{*} \mathrm{c}$. Searches directly under correct screen

E. Search following successive invisible displacements

14. Finding an object following a series of invisible displacements (4)

a. Searches only in E's hand

b. Searches only under first one or two screens in the path

*c. Searches under all screens in the path in the order of hiding

*d. Searches directly under the last screen in the path

15. Finding an object following a series of invisible displacements with evidence of representation (3)

a. Searches only under last screen

b. Searches haphazardly under all screens

*c. Searches systematically from the last screen back to the first

NOTE-The number in parentheses following each task description indicates the number of repetitions of the task recommended by Uzgiris and Hunt. An asterisk indicates the action that must be performed for achievement of a step of the scale. 